\section{A CASE OF CHRONIC CYSTITIS, OCCURRING SEVEN YEARS AFTER LITHOTRITY, CURED BY AN EXCLUSIVELY MILK DIET.}

\author{
BY W. F. TEEVAN, B.A., F.R.C.S.,
}

SURGEON TO THE WEST LONDON AND ST. PETER'S HOSPITALS.

IN May, 1871, I performed lithotrity on James $\mathrm{H}$ aged sixty-eight, at St. Peter's Hospital, and completely got rid of a phosphatic stone in four crushings. The patient was a pale, thin pipe-maker, who had undergone much privation. He remained perfectly well for four years, when he began to have difficulty in micturating, and was very frequently disturbed at night. He then sought my advice. I sounded him, and found that his trouble arose from an enlarged prostate; there was not a particle of stone in the bladder, and the urine was only slightly clouded with mucus. I taught him how to pass a catheter, and he regularly emptied his bladder night and morning with the instrument, enjoying comparative comfort for years.

Last April he again came under my care, complaining that he was always in pain, and that his urine was very thick. His nights were broken, his strength greatly lessened, and he was not able to work. He was treated by various injections, medicines, and washing out the bladder, without relief.

Under these circumstances I determined to try Dr. Geo. Johnson's method of an exclusively milk diet. Having put his alimentary canal in a fit and proper condition for commencing the treatment, the patient began on June $20 \mathrm{th}$ to live on milk alone, taking half a pint every two hours, his urine being then a mass of muco-pus, which adhered tenaciously to the pôt de chambre. He could not pass any arine without the catheter, and was always worried by a dull aching pain above the pubes and in the rectum. The next evening he complained of an acid taste in his mouth, and brought up several pieces of curdled milk.

June 22nd.- Has not vomited since last night. Takes the milk well. Urine not quite so bad as it was.

23rd. - The milk seems to agree well with the patient, who takes about six pints per diem.

26th. - As he felt very faint to-day, he was allowed for one occasion only a thin slice of bread in his milk. Has less pain when he uses the catheter.

29th. - Complains of sickness; brings up curdled milk. Took one dose of bismuth.

30th. - No more sickness.

July 1st.- Is weak, and complains of a sinking sensation at the epigastrium; urine quite clear, acid, sp. gr. 1020; has lost all pain.

5th.-Discharged quite cured of his cystitis.

A month afterwards the patient called at the hospital to say he remained quite well; he had, of course, to use his catheter as usual.

I desire to give to Dr. George Johnson the entire credit of the patient's cure. Although I had always advised patients suffering from any irritation of the urinary tract to live chiefly on milk and fish, I had never previously tried milk exclusively, as recommended by him. I also placed another patient on the milk diet, but although it failed to cure him, it yet greatly relieved his sufferings-so much so, that he said, "I should be quite content to remain as I am." Chronic cystitis being one of the most troublesome complaints to treat, alike unsatisfactory to the patient and surgeon, we must gladly welcome any means of cure, how. ever limited may be its success. But apart from a probable cure of the complaint by milk alone, there is yet another field open for it, as pointed out by Dr. Johnson, and that is the mitigation of the irritation which attends or follows the operation of lithotrity. The influence of an exclusively milk diet on the urinary tract and secretion is well seen in cases of children suffering from incontinence of urine, who can often be cured by simply ordering them to eliminate meat from their dietary and to live on milk only, if possible, or milk and fish, if existence on one aliment cannot be tolerated.

Portman-square, w.
ON THE DIAGNOSIS AND TREATMENT OF IDIOCY, WITH REMARKS ON PROGNOSIS.

BY FLETCHER BEACH, M.B., M.R.C.P., MEDICAL SUPERINTENDENT OY THE DARENTH (LATE CGAPTON) ASYLUY. (Concluded from p. 766.)

I Now proceed to describe cases of acquired imbecility.

1. Eclampsic. - These are cases where convulsions come on during teething, or from some other cause in early life, and though they afterwards cease, they leave the intellect much impaired, and unfortunately capable of little improvement. The remark of Dr. Echeverria is quite true :- "No principle has received a greater sanction from experience than that the earlier the age at which epilepsy springs up, the deeper it undermines the organic and moral constitution, and the more disastrous are its results." E. C- aged sixteen, was delivered with instruments. Epileptic fits came on at the age of twelve months, and continued up to seven years ago. She is very dull, and after three years' treatment has made exceedingly little progress. She can speak and answer questions, and knows a few colours, but she cannot wash or dress herself. She is very listless. Scarcely any improvement can be hoped for.

2. Epileptic.-Under this class are included cases where the epilepsy is the cause of the imbecility. These must be distinguished from those congenital cases which are complicated with occasional attacks of epilepsy, and which need not have an effect upon the intelligence. Improvement will take place if the fits cease; if they do not, there will be deterioration. A boy, aged sixteen, has improved so much as to be discharged "recovered," and is earning his living as a shoemaker. A girl, aged fifteen, made such progress as to be promoted to the position of monitress in the school, notwithstanding a tumour in the brain, of which she died. A little boy, aged nine years, on admission, three years ago, was very wild and unmanageable, but fond of music and singing. There is a history of paralysis and epilepsy on both sides of the family, his father and mother dying of the former disease. He is now a fairly well-conducted boy, has made good progress in the school, and has been put to work as a tailor. The next two cases show the other side of the picture. A boy, aged eleven, on admission three years ago, was able to say a few words, run about, and play. The fits have continued, and increased so much that he has greatly deteriorated. He can only say "stick" and "top." His power of spontaneity has utterly left him. He will sit still for hours together, if allowed, and is almost constantly whining and sorrowful. A girl, aged seventeen, has undergone so much deterioration that she has been discharged from the asylum as incurable. She was passing into a state of utter dementia.

3 and 4. Paralytic and hydrocephalic have been referred to under the head of Congenital Imbecility.

5. Inflammatory. - These are cases prodnced by some disease occurring in infancy or early life, not sufficiently grave to be fatal, but serious enough to cause mental impairment. The first case is that of a boy, aged sixteen, who had whooping-cough and gastric fever when two years and a half old, and since then his intellect has become impaired. The family history is good. He is not epileptic. On admission two years and a half ago he knew a few colours and the simple rules of arithmetic. He has made fair progress in the school, works as a tailor, acts as a page, and plays in the fife and drum band. The next, a little girl, ared eight years, had a serious illness when four years old. She became weak in her mind, and, on admission two years and a half ago, knew nothing. She has made very fair progress in school ; can hem and sew; helps to dress the other children, and is useful in dormitory work. This class of cases usually improves, if not complicated with fits.

5 a. Hypertrophic.-Here there is hypertrophy of the brain-a somewhat rare affection. A boy, aged nine, is an example of this class. His head is enlarged, measuring twenty-two inches in circumference, and somewhat square in shape. He is weak in his legs, speaks slowly, and is epileptic. He has improved a little since admission, but is often dull and scarcely able to speak. He suffers a good deal from headache. He cannot wash or dress himself. In 